\title{
An epigenome-wide association study of posttraumatic stress disorder in US veterans implicates several new DNA methylation loci
}

Mark W. Logue ${ }^{1,2,3,4^{*}}$ D, Mark W. Miller ${ }^{1,2}$, Erika J. Wolf ${ }^{1,2}$, Bertrand Russ Huber ${ }^{1,2}$, Filomene G. Morrison ${ }^{1,2}$, Zhenwei Zhou ${ }^{4}$, Yuanchao Zheng ${ }^{4}$, Alicia K. Smith ${ }^{5,6}$, Nikolaos P. Daskalakis, 7,9,10, Andrew Ratanatharathorn ${ }^{11}$, Monica Uddin ${ }^{12,13}$, Caroline M. Nievergelt ${ }^{14,15,16}$, Allison E. Ashley-Koch ${ }^{17}$, Dewleen G. Baker ${ }^{14,15,18}$, Jean C. Beckham ${ }^{19,20,21}$, Melanie E. Garrett ${ }^{17}$, Marco P. Boks ${ }^{22}$, Elbert Geuze ${ }^{22,23}$, Gerald A. Grant ${ }^{24}$, Michael A. Hauser ${ }^{17}$, Ronald C. Kessler ${ }^{25}$, Nathan A. Kimbrel ${ }^{26,20,21}$, Adam X. Maihofer ${ }^{14,15,16}$, Christine E. Marx ${ }^{27,28,}$ Xue-Jun Qin ${ }^{17}$, Victoria B. Risbrough ${ }^{14,15,16}$, Bart P. F. Rutten ${ }^{29}$, Murray B. Stein ${ }^{14,30,18}$, Robert J. Ursano ${ }^{31}$, Eric Vermetten ${ }^{32,33,34,35}$, Christiaan H. Vinkers ${ }^{36,37}$, Erin B. Ware ${ }^{38}$, Annjanette Stone ${ }^{39}$, Steven A. Schichman ${ }^{39}$, Regina E. McGlinchey ${ }^{40,7}$, William P. Milberg ${ }^{40,7}$, Jasmeet P. Hayes ${ }^{1,2,41}$, Mieke Verfaellie ${ }^{2,42}$ and the Traumatic Stress Brain Study Group

\section{Abstract}

Background: Previous studies using candidate gene and genome-wide approaches have identified epigenetic changes in DNA methylation (DNAm) associated with posttraumatic stress disorder (PTSD).

Methods: In this study, we performed an EWAS of PTSD in a cohort of Veterans ( $n=378$ lifetime PTSD cases and 135 controls) from the Translational Research Center for TBI and Stress Disorders (TRACTS) cohort assessed using the Illumina EPIC Methylation BeadChip which assesses DNAm at more than 850,000 sites throughout the genome. Our model included covariates for ancestry, cell heterogeneity, sex, age, and a smoking score based on DNAm at 39 smoking-associated CpGs. We also examined in EPIC-based DNAm data generated from pre-frontal cortex (PFC) tissue from the National PTSD Brain Bank $(n=72)$.

(Continued on next page)

\footnotetext{
* Correspondence: loguem@bu.edu

${ }^{1}$ National Center for PTSD, VA Boston Healthcare System, Boston, MA, USA

${ }^{2}$ Department of Psychiatry, Boston University School of Medicine, Boston,

MA, USA

Full list of author information is available at the end of the article
}

(C) The Author(s). 2020 Open Access This article is distributed under the terms of the Creative Commons Attribution 4.0 International License (http://creativecommons.org/licenses/by/4.0/), which permits unrestricted use, distribution, and reproduction in any medium, provided you give appropriate credit to the original author(s) and the source, provide a link to the Creative Commons license, and indicate if changes were made. The Creative Commons Public Domain Dedication waiver (http://creativecommons.org/publicdomain/zero/1.0/) applies to the data made available in this article, unless otherwise stated. 
(Continued from previous page)

Results: The analysis of blood samples yielded one genome-wide significant association with PTSD at cg19534438 in the gene GOS2 $\left(p=1.19 \times 10^{-7}, p_{\text {adj }}=0.048\right)$. This association was replicated in an independent PGC-PTSD-EWAS consortium meta-analysis of military cohorts $(p=0.0024)$. We also observed association with the smoking-related locus cg05575921 in AHRR despite inclusion of a methylation-based smoking score covariate $\left(p=9.16 \times 10^{-6}\right)$, which replicates a previously observed PGC-PTSD-EWAS association (Smith et al. 2019), and yields evidence consistent with a smoking-independent effect. The top 100 EWAS loci were then examined in the PFC data. One of the bloodbased PTSD loci, cg04130728 in CHST11, which was in the top 10 loci in blood, but which was not genome-wide significant, was significantly associated with PTSD in brain tissue (in blood $p=1.19 \times 10^{-5}, p_{\text {adj }}=0.60$, in brain, $p=$ 0.00032 with the same direction of effect). Gene set enrichment analysis of the top 500 EWAS loci yielded several significant overlapping GO terms involved in pathogen response, including "Response to lipopolysaccharide" ( $p=$ $6.97 \times 10^{-6}, p_{\text {adj }}=0.042$ ).

Conclusions: The cross replication observed in independent cohorts is evidence that DNA methylation in peripheral tissue can yield consistent and replicable PTSD associations, and our results also suggest that that some PTSD associations observed in peripheral tissue may mirror associations in the brain.

\section{Introduction}

Genetic studies of posttraumatic stress disorder (PTSD) diatheses conducted to date have focused primarily on identifying DNA variants (e.g., single-nucleotide polymorphisms, SNPs) that confer risk for the development of the disorder through candidate gene or genome-wide association studies (GWASs; see, e.g., [1, 2]). More recently, studies have also examined differences between PTSD cases and controls in patterns of gene expression [3] and/or DNA methylation (DNAm [4-6];). DNAm studies involve measurement of a methyl group on the DNA strand at a cytosine-phosphate-guanine (CpG) site, and when this is present in the promoter region of a gene, DNAm tends to be negatively correlated with the expression of the gene. DNAm across the genome can be influenced by a host of genetic and developmental mechanisms, health conditions, and environmental factors ranging from toxin exposure to stress, and it is widely hypothesized to be a mechanism that mediates the effects of trauma exposure on gene expression [7, 8].

Hypothesis and mechanism-focused candidate gene studies have identified PTSD-related differences in DNAm levels in genes associated with the hypothalamicpituitary-adrenal (HPA) axis (e.g., ADCYAP1 [9], FKBP5 [10], and NR3C1 [11]), inflammation (e.g., BDNF [4], HTR2A [12] and $I L-18$ [13]), and neurotransmission (e.g., BDNF [4], HTR2A [14], and HTR3A [15]). Epigenome-wide association studies (EWASs), on the other hand, take a hypothesis-free approach to identifying DNAm loci from across the genome that are statistically associated with the phenotype of interest. To date, only five published PTSD EWASs have reported singlesite associations that survived epigenome-wide multipletesting correction. First, using a DNAm bead chip that interrogated $\sim 27 \mathrm{~K}$ loci in a sample of 100 subjects from an urban community cohort, Smith et al. (2011) reported false discovery rate (FDR)-corrected differences between PTSD cases and controls at loci in 5 genes (ACP5, ANXA2, CLEC9A, TLR8, and TPR) [4]. Second, in a study that used a more comprehensive platform measuring methylation at $\sim 850 \mathrm{~K}$ loci in samples from 96 Australian Vietnam veterans, Mehta et al. (2017) found genome-wide significant associations between DNAm and PTSD in four genes (BRSK1, DOCK2, LCN8, and $N G F$ ) and in one intergenic locus [5]. Rutten et al. (2018) examined pre- to post-deployment changes in DNAm in a cohort of 93 soldiers using a $\sim 450 \mathrm{~K}$ platform and found 17 loci in or near 8 genes that were associated with increasing PTSD symptoms over time [6]. In that study, replication analyses in a similar pre- and post-deployment cohort of 98 soldiers also showed nominal support for findings in 3 genes (HIST1H2APS2, RNF39, and ZFP57). In an EWAS of methylation in sperm cells from a cohort of Veterans (16 with PTSD and 22 controls), Mehta et al. identified three loci reaching genome-wide significance: two intergenic loci and a CpG in CCDC88C [16]. This could point to a possible role of these loci in the inter-generational transmission of the effects of trauma. Finally, Smith et al. [17] recently reported results of the largest PTSD EWAS conducted to date based on a meta-analysis of $n=1896$ participants from 10 cohorts with methylation assessed at $\sim 450 \mathrm{~K}$ loci. Ten loci achieved genome-wide significance, the most significant of which, cg05575921 $\left(p=4.27 \times 10^{-11}\right.$, $\left.\mathrm{FDR}=2.15 \times 10^{-5}\right)$, was located in the smokingassociated gene AHRR. Many of the EWASs of PTSD have also used Gene Set Enrichment Analysis or Functional Network Analysis of genome-wide DNAm as a follow up to their genome-wide association analyses. Significant enrichment has been observed for a number of pathways/biological processes with plausible relevance to PTSD including, most notably, inflammation and 
immune function, HPA axis and glucocorticoid signaling, neurogenesis and neurotransmission, circadian rhythms, and cell adhesion [5, 6, 18-20].

To summarize, prior studies of DNAm associations with PTSD have yielded potentially important insights into the epigenetics of PTSD; however, with several noteworthy limitations. All of them were based on DNAm from peripheral samples (usually blood). Though potentially useful for the development of diagnostic biomarkers, blood samples provide only indirect evidence of epigenetic processes in the brain. In addition, most of the sample sizes studied to date have been modest, and the few EWAS-significant associations that have been reported have been accompanied by limited evidence of replication.

Another major consideration involves the influence of potential confounding variables such as cigarette smoking in PTSD studies. Numerous studies have shown the methylome to be exquisitely sensitive to the effects of smoking. The largest EWAS of cigarette smoking conducted to date by Joehanes et al. $(N \sim 16 \mathrm{~K})$, identified $18760 \mathrm{CpGs}$ on 7201 genes that were differentially methylated in current versus never smokers [21]. Results of that study confirmed numerous prior reports of associations between smoking and DNAm in several genes including, most notably, $A H R R, F 2 R L 3$, and RARA. Because cross-sectional epidemiological studies do not permit inferences about whether DNAm associations are causes, consequences, or effects of third variables, Li et al. (2018) used a genetically informative twin cohort to examine the heritability of the smoking-associated DNAm loci and found strong evidence that most of the observed epigenetic associations were attributable to the effects of cigarette use [22]. These findings are highly relevant to the epigenetics of PTSD because PTSD samples, especially from veteran cohorts, tend to have an elevated prevalence of cigarette smoking relative to the general population [23]. The AHRR locus cg05575921 that was associated with PTSD in the Smith et al. EWAS [17] was also highly significant in both the Joehanes et al. EWAS of smoking [21] and the Li et al EWAS of smoking [22], and in the latter, was the most significant locus. Based on this, Smith et al. also performed analyses stratified by smoking status and found that the association between PTSD and cg05575921 was strongest among non-smokers suggesting an association between PTSD and AHRR independent of smoking.

The aim of this study was to identify individual CpG sites and/or sets of genes associated with PTSD using DNAm data from a veteran cohort and a newlyestablished United States (US) Department of Veterans Affairs (VA) National PTSD Brain Bank [24]. Given the robust associations between smoking and DNAm observed in prior studies, we addressed this important confound by computing a DNAm smoking score based on the top loci from the $\mathrm{Li}$ et al. (2018) study and including it as a covariate in our analyses. The primary analysis was a "Discovery" EWAS of lifetime PTSD diagnosis in DNA from whole blood drawn from a cohort of veterans of the post-9/11 conflicts in Iraq and Afghanistan. We then evaluated evidence for replication of the top EWAS results in (a) an analysis of veterans performed as part of the Smith et al. EWAS, and (b) postmortem pre-frontal cortical tissue from the National PTSD Brain Bank. Finally, we examined candidate gene regions and candidate $\mathrm{CpGs}$ implicated in previous PTSD epigenetic studies.

\section{Materials and methods Discovery Cohort}

The Discovery Cohort was comprised of veterans recruited by the Translational Research Center for TBI and Stress Disorders (TRACTS), a Department of Veterans Affairs Rehabilitation Research and Development (RR\&D) Traumatic Brain Injury Center of Excellence at VA Boston Healthcare System. After applying a quality control pipeline and excluding participants with missing data (see Additional file 1), 541 veterans ( $n=378$ cases and 135 controls) with DNAm data were available for analyses. Demographic characteristics for all three cohorts are listed in Additional file 1: Table S1. The collection of Discovery Cohort data was performed with the approval of a Department of Veterans Affairs human subjects review board and all subjects provided written informed consent.

\section{Consortium Replication Cohort}

We examined results from the recent Smith et al. Consortium EWAS of current PTSD. As it was the closest match to our Discovery Cohort, we requested results from a military cohort meta-analysis. It included 1351 subjects from 7 cohorts: Army Study to Assess Risk and Resilience in Servicemembers (Army STARRS) [25], Marine Resiliency Study (MRS) [26, 27], Prospective Research in Stress-related Military Operations (PRISMO) $[28,29]$, The African American and the European American cohorts from the Mid-Atlantic Mental Illness Research Education and Clinical Center PTSD Study (VA-M-AA and VA-M-EA) [30], the Injury and Traumatic Stress study (INTRuST; see e.g., [31-33]), and the VA Boston Healthcare System National Center for PTSD (VA-NCPTSD) cohort [1]. In the replication cohort analysis, $42 \%$ were current PTSD cases, all of which were assessed with Illumina Infinium HumanMethylation450 BeadChip (450K BeadChips; see Smith et al 2019 for details). As it was not available for many participating cohorts, lifetime PTSD was not analyzed. 


\section{PTSD Brain Bank}

DNA was extracted from the ventromedial prefrontal cortex (vmPFC; Brodmann area 12/32) and dorsolateral prefrontal cortex (dlPFC, Brodmann area 9/46) from 42 PTSD cases and 30 controls. These regions were selected based on findings from functional and structural imaging studies of PTSD suggesting their involvement in the neurobiology of the disorder (see e.g., [34]). A detailed description of the donor identification, postmortem diagnostic assessment procedures, and tissue extraction and processing is presented elsewhere [24, 35] and in Additional file 1.

\section{Generation of genotype and DNAm data}

Genome-wide genotype data were used to generate principal components (PCs) to control for ancestral heterogeneity in each analysis. Genotypes for the Discovery and Brain Bank Cohorts were based on data from Illumina (San Diego CA) HumanOmni2.5-8 BeadChips as described previously $[1,36]$ and in the Supplementary Methods (Additional file 1). DNAm was assessed in the Discovery and the Brain Bank Cohorts using the Illumina EPIC 850K BeadChips. An EWAS consortiumderived pipeline was used to clean the DNAm data from both cohorts [37]. Additional information about the quality control $(\mathrm{QC})$ pipeline is available in Additional file 1.

\section{Data analyses}

Analyses examining associations between DNAm and lifetime PTSD case/control status in the Discovery Cohort were performed with linear models as automated in the Bioconductor limma (Linear Models for Microarray Data) package [38] with the base 2 logit-transformed methylated proportion as the response and PTSD diagnosis as a predictor. Note that we will avoid the use of the term "beta" to refer to coefficient estimates from linear models throughout to avoid confusion with the term beta as it applies to DNAm studies, where it is used to refer to the proportion of DNAm at a given locus. Each limma model included principal components for ancestry, age, sex, estimates of white blood cell proportions, and a DNAm-based "smoking score" as covariates. The latter was based on effect-size estimates for the top-39 probes from a recent smoking EWAS [22]. This score showed highly significant association with self-reported smoking in both the Discovery Cohort and in the VANCPTSD cohort $\left(p<2.2 \times 10^{-16}\right.$ in both cohorts), and was significantly correlated with the number of cigarettes per day in the Discovery Cohort $(r=0.52, p<$ $2.2 \times 10^{-16}$ ). See Supplementary Methods (Additional file 1) for details about computation of the smoking score.

For the EWAS in the Discovery Cohort, we computed false discovery rate [39] corrected $p$-values, also known as Q-values, to control for multiple testing (denoted " $p_{\text {adj }}$ "). We then examined the top 100 associated sites from the EWAS in the $450 \mathrm{~K}$ consortium results and also in the Brain Bank Cohort. In cases in which the observed top associated EPIC locus was not assayed by the 450K BeadChip, when available, we examined correlated "proxy sites" for evidence of replication. A proxy site was defined as a CpG assayed by both EPIC and 450K BeadChips within $5000 \mathrm{bp}$ of a peak EPIC locus that was significantly correlated $(p<0.05)$ to the peak EPIC site. When we observed multiple correlated sites to a peak EPIC locus, we took the one with the highest correlation as the proxy. The genes corresponding to the top 500 sites from the Discovery EWAS were examined for enrichment of specific gene ontology (GO) term categories using the gometh function from the R missMethyl package [40]. This function is an extension of the GOseq method [41] which explicitly models the relationship between the number of $\mathrm{CpG}$ sites measured within a gene and the probability of that gene appearing within the target list, hence avoiding one of the sources of bias which can influence gene set enrichment analyses. Next, we examined candidate genes and $\mathrm{CpG}$ sites previously implicated in studies of DNAm and PTSD. We began by evaluating the significance of the 41 previously implicated CpG sites in blood-based studies of PTSD [4-6, 9, 12, 19, 36, 42, 43] (listed in Additional file 1: Table S2) in the limma EWAS results. Then, we performed a candidate gene examination of 36 previously implicated genes, by examining all sites within a gene from the limma output for association with PTSD using a genewide FDR correction based on the number of probes in each gene.

Post-hoc analyses, including evaluation of the role of smoking in the top EWAS associations and also the effects of other potential confounders (depression, depression severity, selective serotonin reuptake inhibitor use, and alcohol use) in the Discovery Cohort, were performed in $\mathrm{R}$ using the standard package for linear modeling $(\mathrm{lm})$. As DNAm values can be influenced by nearby SNPs, we also examined the possibility of SNP effects for our topassociated loci. We ran a model similar to what was performed in limma above, but which included as a covariate imputed SNP dosage of any nearby genomic variants noted in the Illumina Annotation with minor allele frequency $>5 \%$. See the Supplementary Materials (Additional file 1) for a more complete description of these analyses.

When analyzing the data from the PTSD brain bank, both regions (vmPFC and dIPFC) were analyzed jointly to increase power, reduce multiple testing, and to focus our attention on methylation differences that are consistent across the PFC. A linear mixed model was used which included a random effect to adjust for the correlations of DNAm between the two brain regions in the 
same subject. The model for the PFC included covariates for age, sex, ancestry PCs, and proportion of neurons as estimated from the methylation data [44]. The smoking score when applied to DNAm data from the PFC was found not to correlate with smoking, and indeed, an investigation of smoking in the PFC did not yield any EWASsignificant smoking loci (see Additional file 1 for details). This is consistent with a smaller effect of smoking on methylation in the PFC compared to blood. However, given the modest sample size, we could not exclude such an effect, and smoking as determined by family report and medical history was included as a covariate in the PFC analyses. Although the Brain Bank Cohort was used here primarily to replicate the results from the EWAS performed in blood, we computed the results for the entire genome, so that we could examine the genome-wide distribution of $p$-values for inflated significance. Follow-up analyses in limma examined the dIPFC and vmPFC regions separately to explore whether significant associations were jointly observed across regions.

As we have elsewhere shown that a large proportion of low variation probes have poor correlation across chips due to a low signal-to-noise ratio [45], we excluded probes from the EWAS and candidate gene analyses when the range of the proportion of DNAm was $<0.10$; these were primarily sites where the DNAm proportion was $<0.10$ for all subjects or the DNAm proportion was $>0.90$ for all subjects. This criterion excluded 417,270 of the 819,877 probes passing quality filters (see Additional file 1 for details), leaving 402,607 sites in the blood-based EWAS. However, these low variation probes were analyzed in limma and retained for the purposes of replication of previously reported loci.

\section{Results}

\section{Discovery Cohort EWAS}

There was no evidence of inflation for Discovery EWAS analysis of 402,607 probes (lambda $=1.066$; Additional file 1: Fig. S1). Manhattan plots $(-\log 10 p$-values for each locus plotted relative to their genomic position) are presented in
Fig. 1, and the top 10 most strongly associated loci are listed in Table 1. One epigenome-wide significant association was found involving probe cg19534438 in the G0/G1 Switch 2 gene (GOS2) on chromosome 1 (coefficient $=0.34, p=$ $1.19 \times 10^{-7}, p_{\text {adj }}=0.048$; see Fig. 2a). The other top 10 results included probes in BBS9, RCCD1, NCK1, CHST11, TMLHE, 3 intergenic loci, and $A H R R$ (see Additional file 1: Fig. S2). The $A H R R$ result, involving cg05575921 (Fig. 2b), was particularly noteworthy because this probe was one of the 39 used to compute the DNAm smoking score that was included as a covariate in the EWAS. To clarify the nature of this association and determine if it was an artifact of comorbid cigarette use in the PTSD cases, we performed post-hoc analyses examining the association between this AHRR probe, self-reported smoking, the smoking score, and PTSD under various conditions including (a) a model of PTSD with the smoking score excluded, and (b) a model of PTSD with the smoking score included but with cg05575921 excluded from score calculation. In both cases, the association between cg05575921 and PTSD remained robust $\left(p<10^{-4}\right.$; see Supplementary Results and Additional file 1:Tables S3 and S4 for details). As Smith et al. reported that the association between cg05575921 and PTSD was more significant in non-smokers than in smokers, we performed a similar follow-up analysis of subjects segregated by smoking status. Although cg05575921 was not significant in either smokers or non-smokers, perhaps due to the reduction of sample size, there is a more substantial (negative) effect size estimate for cg05575921 in the non-smokers than the smokers (in non-smokers, coefficient $=-0.13, p=0.059$; in smokers, coefficient $=-0.048, p=0.79$ ). Post-hoc analyses also showed that the EWAS-significant association involving cg19534438 in GOS2, was not affected by the inclusion or exclusion of self-reported smoking or the DNAm-based smoking score in the model (Additional file 1: Table S4).

\section{Consortium Military Replication Cohort}

Of the top 100 loci from our EWAS, consortium 450K meta-analysis results were available for 54 , and proxies

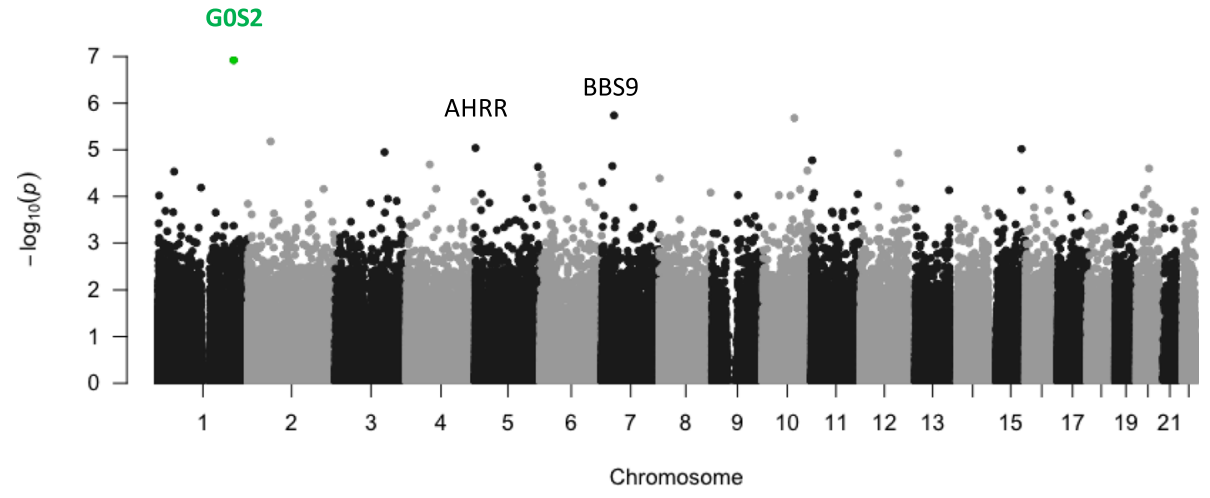

Fig. 1 Manhattan plot of an epigenome-wide association study of PTSD in US Veterans, the one EWAS significant locus at GoS2 is highlighted in green 
Table 1 Top 10 strongest associations from the Discovery Cohort EWAS ( $n=378$ cases and 135 controls)

\begin{tabular}{lllll}
\hline Gene & ID & Coefficient & $p$-value & $p_{\text {adj }}$ \\
\hline GOS2 & cg19534438 & 0.34 & $\mathbf{1 . 1 9 E}-\mathbf{7}$ & $\mathbf{0 . 0 4 8}$ \\
BBS9 & cg20152234 & 0.18 & $1.83 \mathrm{E}-6$ & 0.28 \\
Intergenic & cg11504264 & 0.24 & $2.09 \mathrm{E}-6$ & 0.28 \\
Intergenic & cg08000207 & -0.35 & $6.64 \mathrm{E}-6$ & 0.60 \\
AHRR & cg05575921 & -0.13 & $9.16 \mathrm{E}-6$ & 0.60 \\
RCCD1 & cg25526519 & -0.16 & $9.66 \mathrm{E}-6$ & 0.60 \\
NCK1 & cg09423651 & -0.53 & $1.13 \mathrm{E}-5$ & 0.60 \\
CHST11 & cg04130728 & 0.15 & $1.19 \mathrm{E}-5$ & 0.60 \\
TMLHE & $\mathrm{cg} 12115116$ & 0.25 & $1.53 \mathrm{E}-5$ & 0.68 \\
Intergenic & $\mathrm{cg} 20974659$ & 0.11 & $1.68 \mathrm{E}-5$ & 0.68 \\
\hline
\end{tabular}

were available for an additional 6 . We observed 8 nominally significant associations in the replication cohort, more than would be expected under the null $(p=0.0098$ based on a binomial distribution with $5 \%$ chance of success). Across the 60 loci, the effect size estimates were significantly correlated ( $r=0.39, p=0.0022$, see Fig. 3a). The correlation estimate was higher for the $n=14$ loci with $p<0.10$ in the Replication Cohort (orange and red points in Fig. 3a; $r=0.58, p=0.030$ ) and in the 8 loci with $p<$ 0.05 in the Replication Cohort (red points in Fig. 3a; $r=$ $0.72, p=0.043)$. All loci with $p<0.10$ in the Replication Cohort had the same direction of effect as the Discovery Cohort, which is highly unlikely under the null hypothesis of a $50 \%$ chance of agreement $(p=0.00012)$. Five of the loci assessed in the Replication Cohort remained significant after correcting for the 60 loci examined (Table 2). Unsurprisingly, the $A H R R$ locus noted in our analysis was
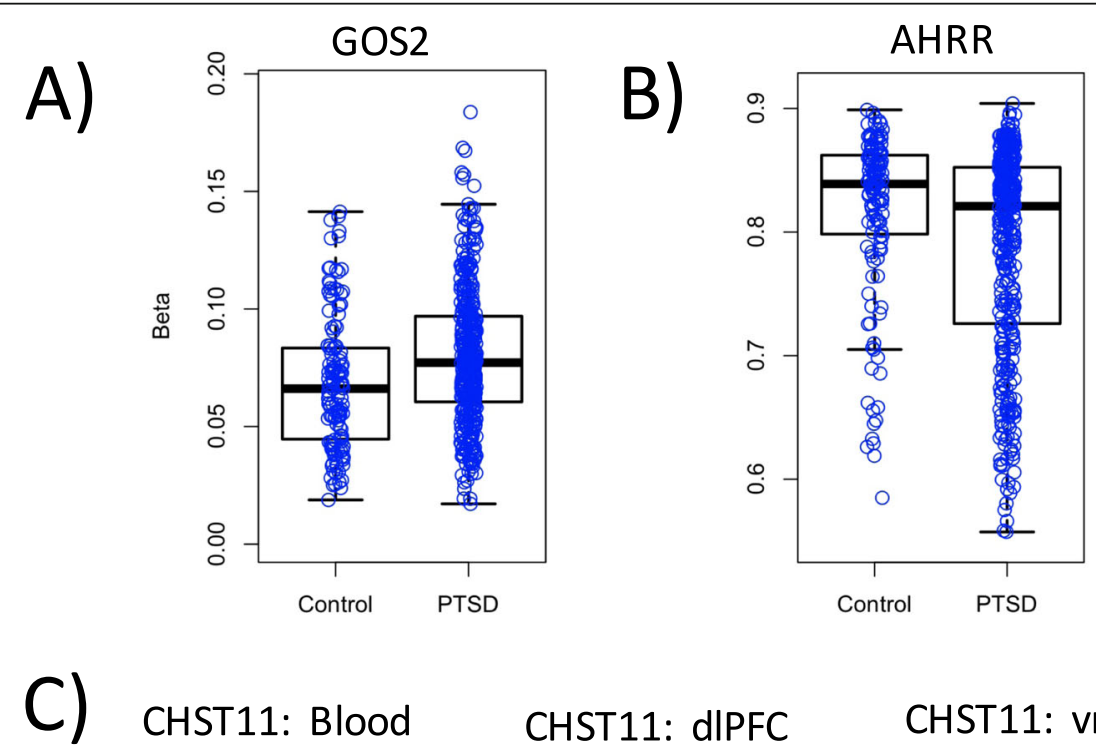

CHST11: dIPFC

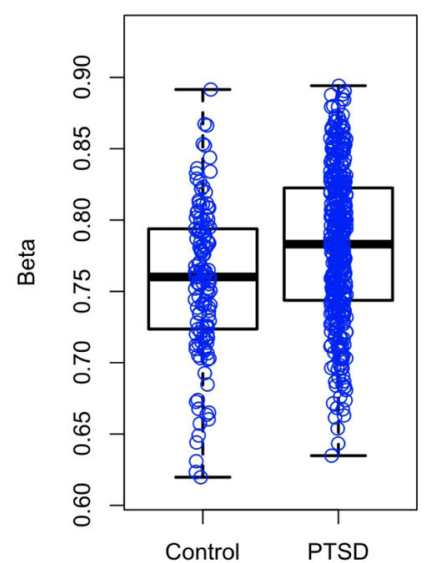

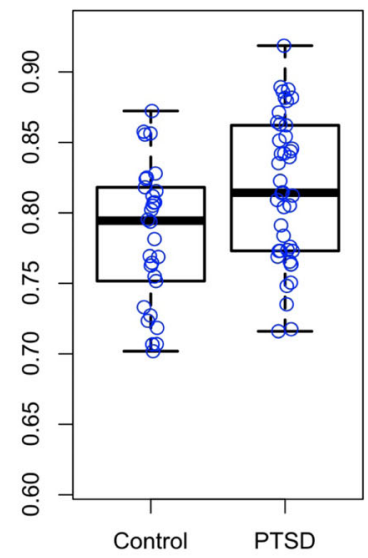

Fig. 2 Box/Scatter plot of the proportion of DNAm (Beta) for (a) cg19534438, the genome-wide significant locus in G0S2, (b) cg05575921, the smoking- and PTSD-associated locus in AHRR, and (c) the CHST11 peak locus from the EWAS of whole-blood samples that was corrected significant in the analysis of tissue from the PFC, with blood, dIPFC, and VMPFC methylation plotted separately. 

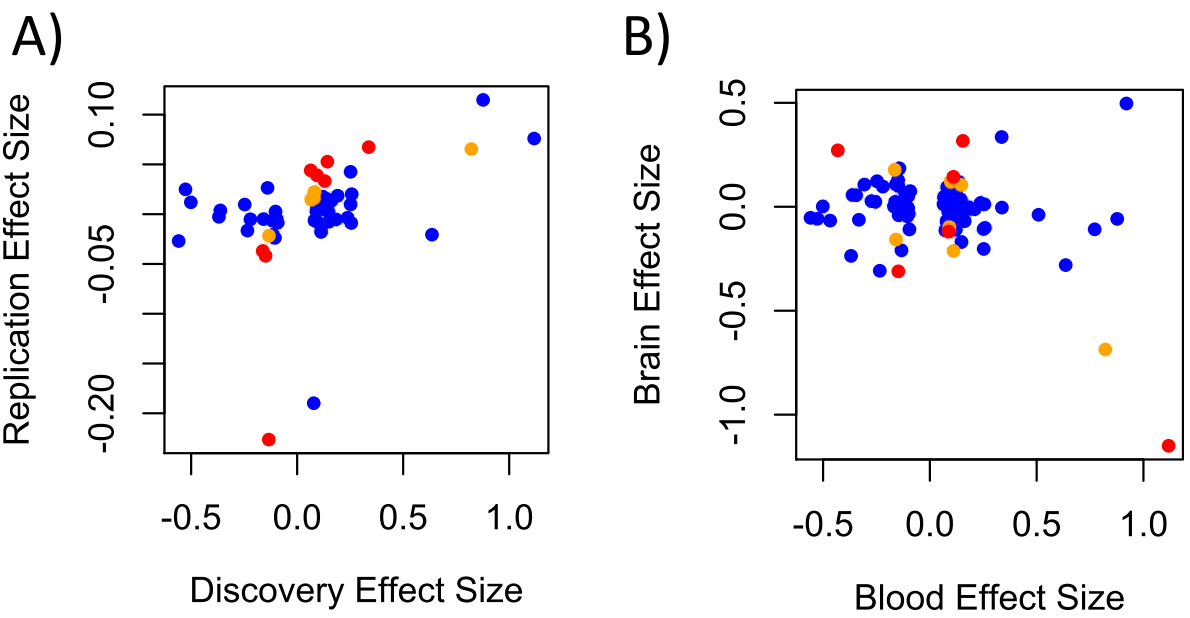

Fig. 3 Effect size estimates compared between (a) the Discovery and the Consortium Military Replication Cohorts, and (b) the Discovery (blood) and the analysis of methylation in the PFC (brain). Loci with $0.05<p<0.10$ are plotted in orange, and loci with $p<0.05$ are plotted in red

significant in the Consortium Military analysis. Two related genes, $A P B A 1$ and $A P B A 2$ also replicated. The $A P B A 1$ association was based on cg13580827, a proxy for the EPIC-only probe cg06826552, while the APBA2 locus was present on both chips. The GOS2 locus, which was genome-wide significant in our EWAS, was likewise associated with PTSD in the Consortium Military Replication Cohort $\left(p=9.18 \times 10^{-4}, p_{\text {adj }}=0.014\right)$. Finally, cg25526519 in the LOC285696 gene also replicated $\left(p=0.0033, p_{\text {adj }}=\right.$ 0.040).

\section{Brain Bank Cohort results}

When we compared the effect size estimates across the Discovery Cohort top 100 EWAS loci in the Brain Bank PFC samples, we did not observe the same correspondence observed between the two blood-based cohorts. In fact, we observed a significant negative correlation $(r=-$ $0.30, p=0.0022$, see Fig. $3 \mathrm{~b}$ ). This was driven primarily by cg12186981 in OR2AG1, which, of the top 100 blood results we attempted to replicate in brain, had the largest effect size estimated in both blood and brain, but with an opposite direction (in blood: effect size $=1.12, p=$
$8.49 \times 10^{-5}$, in brain effect size $\left.=-1.15, p=0.033\right)$. When this point was excluded, the correlation in effect size estimates across blood and brain was still negative, but not significant $(r=-0.096, p=0.334)$. Of the 100 loci examined in the PFC analysis, one, cg04130728 in the CHST11 gene, survived multiple-testing correction (Table 3). This probe was among the top 10 results in the Discovery Cohort, and the direction of effect was the same across the two cohorts. Analysis of the dIPFC and vmPFC separately in limma indicated that the associations observed with CHST11 were consistent across both brain regions (in dlPFC, coefficient $=0.32, p=0.0034$; in vmPFC, coefficient $=0.30, p=0.011$, see Fig. $2 \mathrm{c}$ ). Information on this locus in the Replication Cohort was not available, as it was not assessed on the $450 \mathrm{~K}$ chip, nor were there any correlated proxy sites. This analysis also revealed two nominally significant associations with the same direction of effect across the blood and brain samples, namely, cg11339964 in FBXL7, and cg12186981 in PHACTR (Additional file 1: Fig. S3). Three other nominally significant associations had opposite directions of effect across the discovery and brain bank samples.

Table 2 Probes from the top 100 results in the Discovery EWAS that were significantly associated with PTSD in the Consortium Military Meta-Analysis Replication Cohort

\begin{tabular}{|c|c|c|c|c|c|c|}
\hline \multicolumn{2}{|l|}{ Cohort } & \multicolumn{2}{|c|}{$\begin{array}{l}\text { Discovery } \\
n=513\end{array}$} & \multicolumn{3}{|c|}{$\begin{array}{l}\text { Replication } \\
n=1351\end{array}$} \\
\hline Gene & ID & Coef. & $p$ & Coef. & $p$ & $p_{\text {adj }}$ \\
\hline$\overline{A H R R}$ & cg05575921 & -0.13 & $9.16 \mathrm{E}-6$ & -0.23 & $1.15 E-10$ & $6.90 E-9$ \\
\hline APBA2 & cg27184903 & 0.063 & 0.00023 & 0.044 & $4.51 E-5$ & 0.0013 \\
\hline$A P B A 1$ & $\begin{array}{l}\text { cg06826552/ } \\
\text { proxy cg13580827 }\end{array}$ & $\begin{array}{l}-0.15 / \\
-0.060\end{array}$ & $\begin{array}{l}9.43 E-5 / \\
0.0070\end{array}$ & $\begin{array}{l}\text { NA/ } \\
-0.042\end{array}$ & $\begin{array}{l}\text { NA/ } \\
6.37 \mathrm{E}-5\end{array}$ & $\begin{array}{l}\text { NA/ } \\
0.0013\end{array}$ \\
\hline GOS2 & cg19534438 & 0.34 & $1.19 E-7$ & 0.067 & 0.00092 & 0.014 \\
\hline LOC285696 & cg23987134 & 0.093 & $8.82 E-5$ & 0.039 & 0.0033 & 0.040 \\
\hline
\end{tabular}


Table 3 Probes from the top 100 results in the Discovery EWAS that were nominally associated with PTSD in a combined PFC analysis of dIPFC and vmPFC samples from the Brain Bank Cohort

\begin{tabular}{|c|c|c|c|c|c|c|}
\hline \multirow[b]{2}{*}{ Gene } & \multirow[b]{2}{*}{ ID } & \multicolumn{2}{|l|}{$\begin{array}{l}\text { Discovery } \\
n=513\end{array}$} & \multicolumn{3}{|l|}{$\begin{array}{l}\text { Brain bank } \\
n=72\end{array}$} \\
\hline & & Coefficient & $p$ & Coefficient & $p$ & $p_{\text {adj }}$ \\
\hline CHST11 & cg04130728 & 0.15 & $1.19 E-05$ & 0.32 & 0.00032 & 0.032 \\
\hline$F B X L 7$ & cg11339964 & 0.11 & $1.97 \mathrm{E}-04$ & 0.14 & 0.020 & 0.66 \\
\hline PHACTR & cg19686983 & -0.15 & 0.00017 & -0.31 & 0.030 & 0.66 \\
\hline OR2AG1 & cg12186981 & 1.12 & $8.49 E-05$ & -1.15 & 0.033 & 0.66 \\
\hline C12orf34 & $\mathrm{cg} 02742775$ & 0.087 & $5.18 \mathrm{E}-05$ & -0.12 & 0.042 & 0.66 \\
\hline F9 & cg03155646 & -0.43 & $4.32 \mathrm{E}-05$ & 0.27 & 0.045 & 0.66 \\
\hline
\end{tabular}

Genome-wide analysis of the PFC samples did not yield any evidence of inflated significance (Additional file 1: Fig. S4).

\section{Gene set enrichment analysis}

The gene set enrichment analyses of the top 500 loci from the EWAS of the Discovery Cohort revealed five FDR-corrected significant GO terms (see Table 4). Three of the five (GO:0032496: response to lipopolysaccharide, GO:0002237: response to molecule of bacterial origin, and GO:0071216: cellular response to biotic stimulus) involve pathogen response. The genes in these three categories overlap substantially, with each containing PPARGC1A, TICAM1, TICAM2, IL1B, MEF2C, ABCB4, PRKCE, HAMP, RARA, TFPI, VDR, CDC73, and TNIP3. The other two significant GO terms were GO:0030374: ligand-dependent nuclear receptor transcription coactivator activity and GO:0003416: endochondral bone growth.

\section{Candidate probes and candidate gene regions}

Of the $51 \mathrm{CpG}$ sites with prior reports of association with PTSD (Additional file 1: Table S5), only the AHRR locus reported by Smith et al. survived correction for multiple testing $\left(p_{\text {adj }}=0.00047\right)$, which was not surprising given the fact that cg05575921 was near genomewide significant in our EWAS. Two additional loci showed nominally significant associations in the Discovery Cohort: $\operatorname{cg} 20098659$ in CLEC9A [4] (coefficient =
0.087, $\left.p=0.0098, p_{\text {adj }}=0.25\right)$ and cg02357741 in BRSK1 [5] (coefficient $=0.054, p=0.045, p_{\text {adj }}=0.63$ ). When we examined all of the probes in each of the previously implicated genes (Additional file 1: Table S6), 3 genes showed associations with PTSD that withstood corrections for the number of probes in the respective gene: (a) $A H R R$ (coefficient $=-0.13, p=9.16 \times 10^{-6}$, $p_{\text {adj }}=0.00082$ ); (b) CLEC9A, where the most significant association was with $\operatorname{cg} 02930518$ (coefficient = $0.089, p=0.0067, p_{\text {adj }}=0.040$ ); and (c) COL9A3, where the most significant locus was cg08021508 (coefficient $=-0.16, p=0.00066, p_{\text {adj }}=0.025$ ). However, only the AHRR association would survive a further adjustment for the 41 previously implicated candidate genes examined.

\section{Potential confounders}

See the Supplementary Results and Additional file 1: Table S7 for an examination of potential confouders including depression, anti-depressant use, alcohol-use disorders, and SNP effects. All of the CpGs in Table 1 remain significant after inclusion of each of these covariates. Similarly, the three loci in Tables 1, 2, 3 with nearby $>5 \%$ MAF SNPs remained significant after adjustment for SNP effects. We noted that rs3817870 was a methylation quantitative trait locus (meQTL) for cg19534438 in GOS2 $(p=0.023)$ and $\operatorname{rs} 1550637$ was a meQTL for cg25526519 in RCCD1, but that these SNPs

Table 4 Significant enrichment of GO terms in the top 500 sites from the Discovery Cohort EWAS of PTSD

\begin{tabular}{|c|c|c|c|c|c|c|}
\hline Term & Ont & $N$ & DE & $p$ & $p_{\text {adj }}$ & Genes \\
\hline GO:0032496: response to lipopolysaccharide & $\mathrm{BP}$ & 322 & 19 & $6.97 \mathrm{E}-06$ & 0.042 & $\begin{array}{l}\text { PPARGC1A, CNR2, CPS1, TICAM1, ELANE, FGFR2, FOXP1, TICAM2, IL 1B, } \\
\text { MEF2C, ABCB4, PRKCE, ERBIN, HAMP, RARA, TFPI, VDR, CDC73, TNIP3 }\end{array}$ \\
\hline $\begin{array}{l}\text { GO:0030374: ligand-dependent nuclear } \\
\text { receptor transcription coactivator activity }\end{array}$ & MF & 69 & 9 & $1.12 \mathrm{E}-05$ & 0.042 & PPARGC1A, NCOA7, PPARG, PRKCB, RARA, RARB, RORA, VDR, MED12 \\
\hline $\begin{array}{l}\text { GO:0002237:response to molecule of } \\
\text { bacterial origin }\end{array}$ & $\mathrm{BP}$ & 339 & 19 & $1.42 \mathrm{E}-05$ & 0.042 & $\begin{array}{l}\text { PPARGC1A, CNR2, CPS1, TICAM1, ELANE, FGFR2, FOXP1, TICAM2, ILIB, } \\
\text { MEF2C, ABCB4, PRKCE, ERBIN, HAMP, RARA, TFPI, VDR, CDC73, TNIP3 }\end{array}$ \\
\hline $\begin{array}{l}\text { GO:0071216: cellular response to biotic } \\
\text { stimulus }\end{array}$ & $\mathrm{BP}$ & 202 & 14 & $1.71 E-05$ & 0.042 & $\begin{array}{l}\text { PPARGC1A, TICAM1, TICAM2, IL1B, MEF2C, ABCB4, PRKCE, HAMP, RARA, } \\
\text { TFPI, VDR, WFS1, CDC73, TNIP3 }\end{array}$ \\
\hline GO:0003416: endochondral bone growth & $\mathrm{BP}$ & 22 & 6 & $1.75 E-05$ & 0.042 & FGFR2, POC1A, MSX2, BNC2, RARA, RARB \\
\hline
\end{tabular}


were not confounded with the PTSD associations observed at these two loci.

\section{Discussion}

We performed an EWAS of lifetime PTSD diagnosis using whole blood samples from a cohort of traumaexposed Veterans of the post-9/11 conflicts. We then evaluated evidence for replication using (a) results from a consortium-based meta-analysis of PTSD using military cohorts and (b) DNAm from PFC from a newly established PTSD brain bank. We observed one epigenome-wide significant association involving cg19534438 in the G0/G1 Switch 2 (GOS2) gene. Methylation at this locus showed a positive association with PTSD diagnosis. This was replicated in the consortium meta-analysis with the same direction of effect $(p=$ $\left.0.0024, p_{\text {adj }}=0.037\right)$. There is some prior evidence for a G0S2-PTSD link. In vivo and in vitro studies have shown cortisol to suppress G0S2 [46]. Two prior studies have linked GOS2 expression to PTSD. Specifically, using genome-wide expression profiling in a predator-scent stress animal model of PTSD, Daskalakis et al. (2014) found that GOS2 expression was downregulated in both the amygdala and hippocampus of female rats [47]. Similarly, Bam et al. (2016) identified GOS2 as the most downregulated gene in blood from a genome-wide analysis of RNAseq data from a small cohort of PTSD patients $(n=5)$ and controls $(n=5)$ [48]. The G0S2 protein is well-known for its role in regulating lipid metabolism where it serves as a negative regulator of lipolysis [49, 50]. It has been implicated in mechanisms of obesity, diabetes, aging, and cancer, and linked to gene networks involved in apoptosis, cell communication, and cell death [51]. Because of this, future investigations could examine a potential role of GOS2 in the well-established link between PTSD and metabolic disorders [52, 53].

Although we did not see significant evidence of association between cg19534438 and PTSD in the brain bank data, we note that there is evidence in two online databases that DNAm levels at this locus are correlated between blood and brain. The first database is from the University of Essex (http://epigenetics.essex.ac.uk/bloodbrain/) [54] and includes dual assessment of blood and tissue from four different brain regions: PFC, entorhinal cortex, superior temporal gyrus, and cerebellum with methylation assessed using the $450 \mathrm{~K}$ BeadChip in 80 blood samples and $>100$ samples of tissue for each of the four regions. The second database is ImageCpG, which includes correlations observed in blood, saliva buccal, and brain tissue extracted from epilepsy patients at the University of Iowa [55] assessed with $n=12450 \mathrm{~K}$ and $n=21$ EPIC BeadChips (https://han-lab.org/methylation/default/imageCpG). We note that both databases indicate that there is blood/brain correlation for our peak probe in G0S2 (in ImageCpG $r=0.71, p=0.00048$, in Essex PFC $r=0.31, p=0.0077$, and cerebellum $r=$ $0.27, p=0.026$ ). However, it must be noted that evidence that $\operatorname{cg} 19534438$ is associated with GOS2 expression in blood or in brain tissue is lacking, and this locus could be involved in regulation of some other gene or simply a biomarker of a PTSD associated process. For example, the iMethyl database (http://imethyl.iwate-megabank. org) $[56,57]$ of methylation sites and regulatory effects in peripheral blood mononuclear cells (PBMCs) indicates that this locus is regulatory for the adjacent gene $L A M B 3$ in CD4T cells (effect $=0.0091, p=4.55 \times 10^{-5}$ ). However, both $L A M B 3$ and GOS2 were upregulated in an amyloid $\beta$ peptide stimulation study of microglia, which suggests that they could be co-regulated [58]. Although we are unable to specifically confirm a regulatory effect for this locus, or confirm association in the brain, cg19534438 and GOS2 remain an interesting locus for further study in relationship to PTSD based on the strong convergent evidence of association from two independent sources of data and prior studies associating GOS2 expression to PTSD-related traits.

Methylation at cg05575921 in the Aryl-hydrocarbon Receptor Repressor (AHRR) gene, which was associated with PTSD in Smith et al. 2019, was among the top 10 results from the Discovery EWAS. In this study and in the consortium meta-analysis, PTSD cases showed reduced methylation at this locus compared to controls. The AHRR gene, and cg05575921 in particular, has a well-established association with smoking. The AHR protein is primarily known for its role in xenobiotic metabolism (i.e., metabolism of foreign chemicals generally and aromatic hydrocarbons, specifically). Smoking reduces methylation of $A H R R$, which in turn is associated with increased expression of the gene and enhanced negative feedback inhibition of AHR signaling. DNAm at cg05575921 is one of the strongest and most reliable indicators of smoking in the epigenome [59], but AHRR methylation at this locus, and at other CpG sites within the gene, has also been associated with other phenotypes above and beyond the effects of cigarette smoking, including epigenetic age acceleration (e.g., [60]) and Creactive protein levels (e.g., [61]), both of which have been linked to PTSD in other recent studies [12]. According to iMethyl (accessed Jan 21, 2020), adjacent loci (chr5:373,355 and chr5:373,398) are negatively associated with expression of the AHRR gene in monocytes $\left(p<5 \times 10^{-6}\right)$. Additionally, as reported in Smith et al., methylation at this locus is associated with lower kynurenine and kynurenic acid [17]. Based on the examination of the impact of the smoking score and our follow-up analyses using the score and smoking, we conclude that our data are consistent with a PTSD effect which is independent of the association with smoking. However, we 
note that this will be hard to establish conclusively using human case/control cohorts given the sensitivity of this locus to smoking exposure. For example, even if one were to look at pediatric PTSD in a cohort of children who have never smoked, it is possible that trauma exposure in childhood is associated with increased exposure to second-hand smoke. Therefore, molecular methods (including animal models) may be key in disentangling the association between smoking and $A H R R$ methylation from any putative associations with PTSD and/or trauma exposure. The ImageCpG and Essex databases indicate some level of correlation between blood and brain tissue at this locus (in ImageCpG $r=0.51, p=$ 0.019; in the Essex database PFC $r=0.28, p=0.016$, for other regions $p>0.05$ ). However, we note that this locus was not associated with smoking in the PFC, and the smoking score was not predictive of a history of smoking in the PFC samples (in dIPFC $p=0.44$, in $\operatorname{vmPFC} p=$ 0.38 ).

When we examined the Consortium Military Cohort replication data, two additional loci from our top 100 associated sites were implicated. These were Amyloid beta A4 precursor protein-binding family A member 1 (APBA1) locus cg06826552, through association observed with the $450 \mathrm{~K}$ BeadChip proxy locus cg13580827, and the Amyloid beta A4 precursor protein-binding family A member 2 (APBA2) locus cg27184903. APBA1 on chromosome 9 and $A P B A 2$ on chromosome 15 are expressed in neurons and are involved in protein transport and synaptic function [62]. They play a role in the trafficking of APP, and hence potentially play a role in Alzheimer's disease [62]. APBA1 (also known as MINT1 and X11) has been implicated in a GWAS of cognitive performance and educational attainment from the UK Biobank [63]. It was also differentially expressed in the brains of schizophrenia cases vs controls [64]. Analyses of genomic deletions have implicated $A P B A 2$ (also known as MINT2 and $X 11 L$ ) in autism [65] and schizophrenia [66] pathogenesis. Teschler et al. observed increased methylation at two APBA2 CpGs cg21917349 and cg12044210) in female bipolar cases $(n=24)$ compared to controls $(n=11)$ [67]. While APBA1 and $A P B A 2$ are intriguing PTSD candidate genes, these loci were not genome-wide significant in either the Discovery Cohort or the Consortium Military EWAS, and hence further replication is warranted before these can be considered PTSD loci.

Finally, cg04130728 in the carbohydrate (chondroitin 4) sulfotransferase 11 gene (CHST11) was among the top 10 most strongly associated CpG sites in the Discovery Cohort and this probe associated with PTSD in the PFC at a level that withstood correction for the 100 probes that were examined for replication in the Brain Bank Cohort. CHST11 is an enzyme that is part of a family of carbohydrate sulfotransferases that modify carbohydrate scaffolds involved in mechanisms of extracellular signaling and adhesion. In the brain, CHST11 is involved in generating chondroitin-4-sulfate (C4S), an important component of the brain's extracellular matrix that regulates neuronal plasticity [68], fear learning [69], and neuroinflammation [70]. The cg04130728 locus is not assessed on the $450 \mathrm{~K}$ chip, and we could identify no correlated proxies to examine it in the Smith et al. consortium replication data. We were also therefore unable to examine blood/brain correlation in the Essex database. This locus was available in ImageCpG, which did not indicate significant correlation $(r=0.11, p=0.62)$. However, we note that ImageCpG is limited in the number of samples assessed $(n=21)$, is not brain-region specific, and only contains a small proportion of frontal cortex samples. Therefore, it is quite possible that methylation at this probe displays substantial blood/brain correlation in the PFC, but that more data will be needed from specific Brodmann areas before this can be confirmed. As the iMethyl database was generated using $450 \mathrm{~K}$ data, we were unable to find evidence that this $\mathrm{CpG}$ was associated with CHST11 expression in blood, and we were unable to identify a suitable database for a similar examination of regulatory effects of CHST11 in brain tissue.

Our examination of candidate probes and gene regions implicated in prior studies of the epigenetics of PTSD replicated the prior observed association with the AHRR locus, which was compelling as a candidate locus $\left(p_{\text {adj }}=\right.$ 0.00047) despite its lack of genome-wide significance. None of the other previously implicated probes (listed in Additional file 1: Table S2) yielded effect sizes that survived multiple-testing correction. Several factors may explain why $A H R R$ was the only locus to replicate. First, our primary analyses adjusted for smoking through the use of a DNAm-based smoking score and this was not done in many of the prior PTSD EWASs. Secondly, our clinical cohorts were comprised exclusively of Veterans, the majority of whom were male and most of whom had chronic PTSD. For this reason, our findings may not generalize to other PTSD populations (and vice versa). It is also noteworthy that 12 of the 51 previously implicated loci had low methylation ranges (range $<0.10$; see Additional file 1: Table S6), which could make them unreliable and/or difficult to replicate [45].

\section{Conclusions}

The replication of the AHRR locus implicated in the PTSD-consortium EWAS in the discovery cohort, the replication of GOS2, the top locus from this EWAS, in the Consortium Military Meta-Analysis, and the broader evidence of agreement in effect size direction for the Discovery Cohort and the Replication Cohort are cause for renewed optimism in the search for reliable blood 
methylation-based PTSD biomarkers. In many largescale consortium GWAS studies from the PGC, there was an inflection point past which increasing sample size produced an increasing number of replicable loci. Although it may well be that PTSD DNAm signatures will differ by sex, trauma type, and other demographic factors, these replicated loci may indicate that a similar tipping point has been reached in large sample EWASs of PTSD. Further, this study adds to the growing body of evidence of disruption to inflammation and immune response processes in the pathophysiology of PTSD.

\section{Supplementary information}

Supplementary information accompanies this paper at https://doi.org/10. 1186/s13148-020-0820-0.

Additional file 1. Supplementary methods and results.

Additional file 2. Complete EWAS results for the Discovery Cohort.

Additional file 3. Replication of top EWAS resultsin the PFC of the Brain Bank Cohort.

\section{Abbreviations}

450K BeadChip: Illumina Infinium HumanMethylation450 BeadChip; CpG: Cytosine-phosphate-guanine site; dIPFC: Dorsolateral prefrontal cortex; DNA: Deoxyribonucleic acid; DNAm: DNA methylation; EPIC: Illumina EPIC Methylation BeadChip; EWAS: Epigenome-wide association study; FDR: False discovery rate; GO: Gene ontology; GWAS: Genome-wide association study; HPA axis: Hypothalamic-pituitary-adrenal axis; $p$ : $p$-value; $p_{\text {adj: }}$ False-discovery rate corrected $p$-value; PFC: Prefrontal cortex; PGC: Psychiatric Genomics Consortium; PTSD: Posttraumatic stress disorder; QC: Quality control; SNP: Single-nucleotide polymorphism; TBI: Traumatic brain injury; TRACTS: Translational Research Center for TBI and Stress Disorders; VmPFC: Ventromedial prefrontal cortex

\section{Acknowledgements}

The MRS study would like to acknowledge Victoria B. Risbrough Ph.D (VA San Diego Healthcare System \& UCSD), Mark A. Geyer (UCSD), Daniel T. O'Connor (UCSD), all MRS investigators, as well as the MRS administrative core and data collection staff listed in the Methods article (Baker et al, Prev Chronic Dis. 2012;9(10):E97), and to thank the Marine and Navy Corpsmen volunteers for their military service and participation in MRS. The Army STARRS Team consists of the following: Co-Principal Investigators, Robert J. Ursano, MD (Uniformed Services University of the Health Sciences) and Murray B. Stein, MD, MPH (University of California San Diego and VA San Diego Healthcare System); Site Principal Investigators, Steven Heeringa, PhD (University of Michigan), James Wagner, PhD (University of Michigan), and Ronald C. Kessler, PhD (Harvard Medical School); Army liaison/consultant, Kenneth Cox, MD, MPH (US Army Public Health Center); other team members, Pablo A. Aliaga, MS (Uniformed Services University of the Health Sciences), COL David M. Benedek, MD (Uniformed Services University of the Health Sciences); Susan Borja, PhD (NIMH); Tianxi Cai, ScD (Harvard School of Public Health); Laura Campbell-Sills, PhD (University of California San Diego); Chia-Yen Chen, ScD (Harvard Medical School); Carol S. Fullerton, PhD (Uniformed Services University of the Health Sciences); Nancy Gebler, MA (University of Michigan); Joel Gelernter, MD (Yale University); Robert K. Gifford, PhD (Uniformed Services University of the Health Sciences); Feng He, MS (University of California San Diego); Paul E. Hurwitz, MPH (Uniformed Services University of the Health Sciences); Sonia Jain, PhD (University of California San Diego); Kevin Jensen, PhD (Yale University); Kristen Jepsen, PhD (University of California San Diego); Tzu-Cheg Kao, PhD (Uniformed Services University of the Health Sciences); Lisa Lewandowski-Romps, PhD (University of Michigan); Holly Herberman Mash, PhD (Uniformed Services University of the Health Sciences); James E. McCarroll, PhD, MPH (Uniformed Services University of the Health Sciences); Adam X. Maihofer (University of California San Diego); Colter Mitchell, PhD (University of Michigan); James A. Naifeh, PhD (Uniformed
Services University of the Health Sciences); Tsz Hin Hinz Ng, MPH (Uniformed Services University of the Health Sciences); Caroline M. Nievergelt, PhD (University of California San Diego); Matthew K. Nock, PhD (Harvard University); Stephan Ripke, MD (Harvard Medical School); Nancy A. Sampson, BA (Harvard Medical School); CDR Patcho Santiago, MD, MPH (Uniformed Services University of the Health Sciences); Ronen Segman, MD (Hadassah University Hospital, Israel); Jordan W. Smoller, MD, ScD (Harvard Medical School); Xiaoying Sun, MS (University of California San Diego); Erin Ware PhD (University of Michigan); LTC Gary H. Wynn, MD (Uniformed Services University of the Health Sciences); Alan M. Zaslavsky, PhD (Harvard Medical School); and Lei Zhang, MD (Uniformed Services University of the Health Sciences). Members of the INTRuST Consortium Biorepository Working Group include Gerald A. Grant, MD, Christine E. Marx, MD, Mark S. George, MD, Thomas W. McAllister, MD, Norberto Andaluz, MD, Lori Shutter, MD, Raul Comibra, MD, Ross D. Zafonte, DO, Sonia Jain, PhD, Xue-Jun Qin, and Michael Hauser, PhD. The Mid-Atlantic MIRECC Workgroup contributors include Mira Brancu, PhD, Patrick S. Calhoun, PhD, Eric Dedert, PhD, Eric B. Elbogen, PhD, John A. Fairbank, PhD, Robin A. Hurley, MD, Jason D. Kilts, PhD, Angela Kirby, MS, Christine E. Marx, MD, MS, Scott D. McDonald, PhD, Scott D. Moore, MD, PhD, Rajendra A. Morey, MD, MS, Jennifer C. Naylor, PhD, Treven C. Pickett, PsyD, Jared Rowland, PhD, Cindy Swinkels, PhD, Steven T. Szabo, MD, PhD, Katherine H. Taber, PhD, Larry A. Tupler, PhD, Elizabeth E. Van Voorhees, PhD, H. Ryan Wagner, Ph.D., Ruth E. YoashGantz, PsyD.

"The Traumatic Stress Brain Research Group (exclusive of previously named authors) are: Matthew J. Friedman MD, PhD (Director) ${ }^{43,44}$, Victor E. Alvarez MD ${ }^{43,45,46}$, David Benedek MD ${ }^{47}$, Christopher Brady PhD ${ }^{43,45,46}$, Dianne Cruz MS ${ }^{48}$, David A Davis PhD ${ }^{49}$, Ronald S. Duman PhD ${ }^{43,50,51}$, Matthew J. Girgenti ${ }^{50,51}$, PhD, Melanie Hardegree RN ${ }^{50}$, Paul E. Holtzheimer MD ${ }^{43,44}$, Terence M. Keane PhD ${ }^{43,45,46}$, Neil Kowell MD ${ }^{45,46}$, John H. Krystal MD 43,50,51, Ann McKee MD ${ }^{45,46}$, Brian Marx PhD 43,45,46, Deborah Mash PhD ${ }^{52}$, William K. Scott PhD ${ }^{49}$, Thor Stein MD ${ }^{45,46}$, PhD, Robert Ursano MD ${ }^{47}$, Douglas E. Williamson PhD ${ }^{48,53}$, Keith A. Young PhD ${ }^{54}$."

43. National Center for PTSD. ${ }^{44}$. Department of Psychiatry, Geisel School of Medicine at Dartmouth. ${ }^{45}$. Departments of Psychiatry, Neurology, and/or Pathology \& Laboratory Science, Boston University. ${ }^{46 .}$ VA Boston Healthcare System. ${ }^{47}$. Department of Psychiatry, Uniformed Services University of Health Science. ${ }^{48 .}$ Department of Psychiatry \& Behavioral Sciences, Duke University Medical Center. ${ }^{49}$ Departments of Human Genetics, Public Health Sciences and/ or Neurology, University of Miami Miller School of Medicine. ${ }^{50}$. Department of Psychiatry, Yale University School of Medicine. ${ }^{51 .}$ VA Connecticut Healthcare System. ${ }^{52}$. Department of Biomedical Sciences, Nova Southeastern University. ${ }^{53}$. Durham VA Healthcare System. ${ }^{54}$.Department of Psychiatry \& Behavioral Science, Texas A\&M University System Health Science Center.

\section{Authors' contributions}

Authors MWL, MWM, EJW, BRH, FGM, AKS, and NPD contributed to study design, data interpretation, and drafting of the manuscript. $M W L, Z Z$, and $Y Z$ analyzed data and/or prepared figures and tables for the manuscript. MU, CMN, AEA-K, DGB, JCB, MEG, MPB, EG, GAG, MAH, RCK, NAK, AXM, CEM, X-JQ, $V B R, B P F R, M B S, R J U, E V, C H V$, and EBW contributed to the consortium metaanalysis used for replication. AS and SAS contributed to the generation of the DNAm data for the TRACTS study. REM, WPM, JPH, and MV supplied samples and phenotype data used in the study. All authors reviewed and approved the manuscript prior to submission.

\section{Funding}

This work was funded by 101BX003477, a Department of Veterans Affairs BLR\&D grant to MWL, 1R03AG051877, 1R21AG061367-01, and 1I01CX00127601A2 to EJW, 5T32MH019836-18 to FGM, R21MH102834 to MWM, 1 R01MH108826 to Smith/Logue/Nievergelt/Uddin, the National Center for PTSD: Behavioral Sciences Division, and the Translational Research Center for TBI and Stress Disorders (TRACTS), a Department of Veterans Affairs Rehabilitation Research and Development (RR\&D) Traumatic Brain Injury Center of Excellence (B3001-C) at VA Boston Healthcare System. Genotype and methylation data for the TRACTS and Brain Bank Cohort was generated with the support of resources and of facilities at the Pharmacogenomics Analysis Laboratory (Research Service, Central Arkansas Veterans Healthcare System, Little Rock, Arkansas), a core research laboratory funded by the Cooperative Studies Program, Research and Development, Department of Veterans Affairs. Marine Resiliency Study (MRS) funding from The Marine Corps, Navy Bureau of Medicine and Surgery (BUMED) and VA Health Research and Development (HSR\&D) who provided funding for MRS data collection and analysis (PI DGB) 
and $\mathrm{NIH}$ R01MH093500 which funded the GWAS assays and analysis (PI CMN). Army STARRS was sponsored by the Department of the Army and funded under cooperative agreement number U01MH087981 (2009-2015) with the National Institutes of Health, National Institute of Mental Health ( $\mathrm{NIH} / \mathrm{NIMH})$. Subsequently, STARRS-LS was sponsored and funded by the Department of Defense (USUHS grant no. HU0001-15-2-0004). Data collection of PRISMO was funded by the Dutch Ministry of Defence, and DNA methylation analyses in PRISMO were funded by the VENI Award fellowship from the Netherlands Organisation for Scientific Research (NWO, grant no. 916.11.086). The PTSD and TBI Injury and Traumatic Stress Clinical Consortium (INTRuST) was funded by a grant from the US Department of Defense (PI: Stein, MB): W81XWH08-2-0159. Mid-Atlantic Mental Illness Research Education and Clinical Center the study of Post-Deployment Mental Health Study funding included a Clinical Sciences Research and Development (CSR\&D) Research Career Scientist Award (\#11SRCS-009) to Dr. Beckham, a CSR\&D Career Development Award (\#IK2 CX000525) to Dr. Kimbrel, and Biomedical and Laboratory Research and Development (BLR\&D) Merit Award to Dr. Beckham from the US Department of Veterans Affairs (VA). This work was also supported by the VA Mid-Atlantic Mental IIIness Research, Education and Clinical Center (MIRECC), the Durham Veterans Affairs Medical Center, the VA Office of Mental Health Services, and the VA Office of Research and Development.

\section{Availability of data and materials}

A complete set of the results of the EWAS in the TRACTS study, and the results of the top 100 loci examined in the PFC analysis are presented in Additional file 2 and Additional file 3. Due to the provisions of the informed consent documents for this study, individual-level data cannot be posted publicly; however, those data may be obtained via a data-use agreement with the TRACTS study. Contact Dr. Regina McGlinchey (Regina_McGlinchey@hms.harvard.edu) to request access.

\section{Ethics approval and consent to participate}

This research was performed under the supervision and approval of US Department of Veterans Affairs human subjects review board. All participants supplied written informed consent.

\section{Consent for publication}

\section{Not applicable}

\section{Competing interests}

FM participated in this study while also an NIMH-funded research postdoctoral fellow at Boston University/NA Boston Healthcare System, but is currently an employee of BlackThorn Therapeutics. MBS has in the past 3 years been a consultant for Actelion, Aptinyx, Bionomics, Dart Neuroscience, Healthcare Management Technologies, Janssen, Neurocrine Biosciences, Oxeia Biopharmaceuticals, Pfizer, and Resilience Therapeutics. In the past 3 years, RCK received support for his epidemiological studies from Sanofi Aventis; was a consultant for DataStat, Inc., Johnson \& Johnson Wellness and Prevention, Sage Pharmaceuticals, Shire, Takeda; and served on an advisory board for the Johnson \& Johnson Services Inc. Lake Nona Life Project. None of the remaining authors have any conflicts to disclose. The views expressed in this article are those of the authors and do not necessarily reflect the position or policy of the Department of Veterans Affairs, the Department of Defense, NIMH, or the US government.

\section{Author details}

${ }^{1}$ National Center for PTSD, VA Boston Healthcare System, Boston, MA, USA. ${ }^{2}$ Department of Psychiatry, Boston University School of Medicine, Boston, MA, USA. ${ }^{3}$,Biomedical Genetics, Boston University School of Medicine, Boston, MA, USA. ${ }^{4}$ Department of Biostatistics, Boston University School of Public Health, Boston, MA, USA. ${ }^{5}$ Department of Gynecology and Obstetrics, Emory University, Atlanta, GA, USA. ${ }^{6}$ Department of Psychiatry and Behavioral Sciences, Emory University, Atlanta, GA, USA. ${ }^{7}$ Department of Psychiatry, Harvard Medical School, Boston, MA, USA. ${ }^{8}$ McLean Hospital, Belmont, MA, USA. ${ }^{9}$ Cohen Veterans Bioscience, Cambridge, MA, USA. ${ }^{10}$ Department of Psychiatry, Icahn School of Medicine at Mount Sinai, New York, NY, USA. ${ }^{11}$ Department of Epidemiology, Columbia University, New York, NY, USA. ${ }^{12}$ Genomics Program, University of South Florida College of Public Health, Tampa, FL, USA. ${ }^{13}$, Global Health and Infectious Disease Research Program, University of South Florida College of Public Health, Tampa, FL, USA.

${ }^{14}$ Department of Psychiatry, University of California San Diego, La Jolla, CA,
USA. ${ }^{15}$ Center of Excellence for Stress and Mental Health, Veterans Affairs San Diego Healthcare System, San Diego, CA, USA. ${ }^{16}$ Research Service, Veterans Affairs San Diego Healthcare System, San Diego, CA, USA. ${ }^{17}$ Duke Molecular Physiology Institute, Duke University Medical Center, Durham, NC, USA. ${ }^{18}$ Psychiatry Service, Veterans Affairs San Diego Healthcare System, San Diego, CA, USA. ${ }^{19}$ Department of Psychiatry and Behavioral Sciences, Duke University, Durham, NC, USA. ${ }^{20}$ Research, Durham VA Medical Center, Durham, NC, USA. ${ }^{21}$ Genetics Research Laboratory, VA Mid-Atlantic Mental Illness Research, Education, and Clinical Center (MIRECC), Durham, NC, USA. ${ }^{22}$ Department of Psychiatry, UMC Utrecht Brain Center, Utrecht, Utrecht, Netherlands. ${ }^{23}$ Brain Research and Innovation Centre, Netherlands Ministry of Defence, Utrecht, Utrecht, Netherlands. ${ }^{24}$ Department of Neurosurgery, Stanford University Medical Center, Stanford, CA, USA. ${ }^{25}$ Department of Health Care Policy, Harvard Medical School, Boston, MA, USA. ${ }^{26}$ Duke Molecular Physiology Institute, Duke University, Durham, NC, USA.

${ }^{27}$ Department of Critical Care Medicine, Neurology, and Neurosurgery, University of Pittsburgh, Pittsburgh, PA, USA. ${ }^{28}$ Department of Psychiatry \& Behavioral Sciences, Duke University Medical Center, Durham, NC, USA.

${ }^{29}$ School for Mental Health and Neuroscience, Department of Psychiatry and Neuropsychology, Maastricht Universitair Medisch Centrum, Maastricht, Limburg, Netherlands. ${ }^{30}$ Million Veteran Program, Veterans Affairs San Diego Healthcare System, San Diego, CA, USA. ${ }^{31}$ Department of Psychiatry, Uniformed Services University, Bethesda, MD, USA. ${ }^{32}$ Arq, Psychotrauma Reseach Expert Group, Diemen, NH, Netherlands. ${ }^{33}$ Department of Psychiatry, Leiden University Medical Center, Leiden, ZH, Netherlands. ${ }^{34}$ Netherlands Defense Department, Research Center, Utrecht, UT, Netherlands.

${ }^{35}$ Department of Psychiatry, New York University School of Medicine, New York, NY, USA. ${ }^{36}$ Department of Anatomy and Neurosciences, Amsterdam UMC (location VUmc), Amsterdam, Holland, Netherlands. ${ }^{37}$ Department of Psychiatry, Amsterdam UMC (location VUmc), Amsterdam, Holland, Netherlands. ${ }^{38}$ Institute for Social Research, Survey Research Center, University of Michigan, Michigan, MI, USA. ${ }^{39}$ Pharmacogenomics Analysis Laboratory, Research Service, Central Arkansas Veterans Healthcare System, Little Rock, AR, USA. ${ }^{40}$ Geriatric Research Educational and Clinical Center and Translational Research Center for TBI and Stress Disorders, VA Boston Health Care System, Boston, MA, USA. ${ }^{41}$ Department of Psychology and Chronic Brain Injury Program, The Ohio State University, Columbus, OH, USA.

${ }^{42}$ Memory Disorders Research Center, VA Boston Healthcare System and Boston University School of Medicine, Boston, MA, USA.

Received: 31 October 2019 Accepted: 29 January 2020

Published online: 14 March 2020

\section{References}

1. Logue MW, Baldwin C, Guffanti G, Melista E, Wolf EJ, Reardon AF, Uddin M, Wildman D, Galea S, Koenen KC, Miller MW. A genome-wide association study of post-traumatic stress disorder identifies the retinoid-related orphan receptor alpha (RORA) gene as a significant risk locus. Mol Psychiatry. 2013; 18:937-42.

2. Nievergelt CM, Maihofer AX, Klengel T, Atkinson EG, Chen CY, Choi KW, Coleman JRI, Dalvie S, Duncan LE, Gelernter J, et al. International metaanalysis of PTSD genome-wide association studies identifies sex- and ancestry-specific genetic risk loci. Nat Commun. 2019;10:4558.

3. Logue MW, Smith AK, Baldwin C, Wolf EJ, Guffanti G, Ratanatharathorn A, Stone A, Schichman SA, Humphries D, Binder EB, et al. An analysis of gene expression in PTSD implicates genes involved in the glucocorticoid receptor pathway and neural responses to stress. Psychoneuroendocrinology. 2015: 57:1-13.

4. Smith AK, Conneely KN, Kilaru V, Mercer KB, Weiss TE, Bradley B, Tang Y, Gillespie CF, Cubells JF, Ressler KJ. Differential immune system DNA methylation and cytokine regulation in post-traumatic stress disorder. Am J Med Genet B Neuropsychiatr Genet. 2011;156B:700-8.

5. Mehta D, Bruenig D, Carrillo-Roa T, Lawford B, Harvey W, Morris CP, Smith AK, Binder EB, Young RM, Voisey J. Genomewide DNA methylation analysis in combat veterans reveals a novel locus for PTSD. Acta Psychiatr Scand. 2017;136:493-505.

6. Rutten BPF, Vermetten E, Vinkers $C H$, Ursini G, Daskalakis NP, Pishva E, de Nijs L, Houtepen LC, Eijssen L, Jaffe AE, et al. Longitudinal analyses of the DNA methylome in deployed military servicemen identify susceptibility loci for post-traumatic stress disorder. Mol Psychiatry. 2018;23:1145-56. 
7. Szyf M, Tang YY, Hill KG, Musci R. The dynamic epigenome and its implications for behavioral interventions: a role for epigenetics to inform disorder prevention and health promotion. Transl Behav Med. 2016;6:55-62.

8. Zannas AS, Provencal N, Binder EB. Epigenetics of posttraumatic stress disorder: current evidence, challenges, and future directions. Biol Psychiatry. 2015;78:327-35.

9. Ressler KJ, Mercer KB, Bradley B, Jovanovic T, Mahan A, Kerley K, Norrholm SD, Kilaru V, Smith AK, Myers AJ, et al. Post-traumatic stress disorder is associated with PACAP and the PAC1 receptor. Nature. 2011;470:492-7.

10. Klengel T, Mehta D, Anacker C, Rex-Haffner M, Pruessner JC, Pariante CM, Pace TW, Mercer KB, Mayberg HS, Bradley B, et al. Allele-specific FKBP5 DNA demethylation mediates gene-childhood trauma interactions. Nat Neurosci. 2013;16:33-41

11. Yehuda R, Daskalakis NP, Desarnaud F, Makotkine I, Lehrner AL, Koch E, Flory JD, Buxbaum JD, Meaney MJ, Bierer LM. Epigenetic biomarkers as predictors and correlates of symptom improvement following psychotherapy in combat veterans with PTSD. Front Psychiatry. 2013:4:118

12. Miller MW, Maniates H, Wolf EJ, Logue MW, Schichman SA, Stone A, Milberg W, McGlinchey R. CRP polymorphisms and DNA methylation of the AIM2 gene influence associations between trauma exposure, PTSD, and C-reactive protein. Brain Behav Immun. 2018:67:194-202.

13. Rusiecki JA, Byrne C, Galdzicki Z, Srikantan V, Chen L, Poulin M, Yan L, Baccarelli A. PTSD and DNA methylation in select immune function gene promoter regions: a repeated measures case-control study of U.S. military service members. Front Psychiatry. 2013;4:56.

14. Parade SH, Novick AM, Parent J, Seifer R, Klaver SJ, Marsit CJ, Gobin AP, Yang BZ, Tyrka AR. Stress exposure and psychopathology alter methylation of the serotonin receptor 2A (HTR2A) gene in preschoolers. Dev Psychopathol. 2017;29:1619-26.

15. Schechter DS, Moser DA, Pointet VC, Aue T, Stenz L, Paoloni-Giacobino A, Adouan W, Manini A, Suardi F, Vital M, et al. The association of serotonin receptor $3 \mathrm{~A}$ methylation with maternal violence exposure, neural activity, and child aggression. Behav Brain Res. 2017;325:268-77.

16. Mehta D, Pelzer ES, Bruenig D, Lawford B, McLeay S, Morris CP, Gibson JN, Young RM, Voisey J, Initiative P. DNA methylation from germline cells in veterans with PTSD. J Psychiatr Res. 2019;116:42-50.

17. Smith AK, Ratanatharathorn A, Maihofer AX, Naviaux RK, Aiello AE, Amstadter AB, Ashley-Koch AE, Baker DG, Beckham JC, Boks MP, et al. Epigenome-wide meta-analysis of PTSD across 10 military and civilian cohorts identifies novel methylation loci. BioRxiv. 2019; https://doi.org/10. $1101 / 585109$.

18. Hammamieh R, Chakraborty N, Gautam A, Muhie S, Yang R, Donohue D, Kumar R, Daigle BJ Jr, Zhang Y, Amara DA, et al. Whole-genome DNA methylation status associated with clinical PTSD measures of OIF/OEF veterans. Transl Psychiatry. 2017;7:e1169.

19. Kuan PF, Waszczuk MA, Kotov R, Marsit CJ, Guffanti G, Gonzalez A, Yang X,

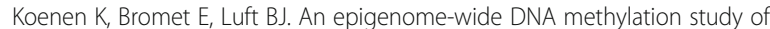
PTSD and depression in World Trade Center responders. Transl Psychiatry. 2017;7:e1158

20. Uddin M, Aiello AE, Wildman DE, Koenen KC, Pawelec G, de Los SR, Goldmann E, Galea S. Epigenetic and immune function profiles associated with posttraumatic stress disorder. Proc Natl Acad Sci U S A. 2010;107:9470-5

21. Joehanes R, Just AC, Marioni RE, Pilling LC, Reynolds LM, Mandaviya PR, Guan W, Xu T, Elks CE, Aslibekyan S, et al. Epigenetic signatures of cigarette smoking. Circ Cardiovasc Genet. 2016;9:436-47.

22. Li S, Wong EM, Bui M, Nguyen TL, Joo JE, Stone J, Dite GS, Giles GG, Saffery $\mathrm{R}$, Southey MC, Hopper JL. Causal effect of smoking on DNA methylation in peripheral blood: a twin and family study. Clin Epigenetics. 2018;10:18.

23. Fu SS, McFall M, Saxon AJ, Beckham JC, Carmody TP, Baker DG, Joseph AM. Post-traumatic stress disorder and smoking: a systematic review. Nicotine Tob Res. 2007:9:1071-84

24. Friedman MJ, Huber BR, Brady CB, Ursano RJ, Benedek DM, Kowall NW, McKee AC. Traumatic Stress Brain Research G: VA's National PTSD Brain Bank: a National Resource for Research. Curr Psychiatry Rep. 2017;19:73.

25. Stein MB, Chen CY, Ursano RJ, Cai T, Gelernter J, Heeringa SG, Jain S, Jensen KP, Maihofer AX, Mitchell C, et al. Genome-wide association studies of posttraumatic stress disorder in 2 cohorts of US army soldiers. JAMA Psychiatry. 2016;73:695-704.

26. Nievergelt CM, Maihofer AX, Mustapic M, Yurgil KA, Schork NJ, Miller MW, Logue MW, Geyer MA, Risbrough VB, O'Connor DT, Baker DG. Genomic predictors of combat stress vulnerability and resilience in U.S. marines: a genome-wide association study across multiple ancestries implicates PRTFDC1 as a potential PTSD gene. Psychoneuroendocrinology. 2015;51: 459-71.

27. Baker DG, Nash WP, Litz BT, Geyer MA, Risbrough VB, Nievergelt CM, O'Connor DT, Larson GE, Schork NJ, Vasterling JJ, et al. Predictors of risk and resilience for posttraumatic stress disorder among ground combat Marines: methods of the Marine Resiliency Study. Prev Chronic Dis. 2012;9:E97.

28. Boks MP, van Mierlo HC, Rutten BP, Radstake TR, De Witte L, Geuze E, Horvath S, Schalkwyk LC, Vinkers CH, Broen JC, Vermetten E. Longitudinal changes of telomere length and epigenetic age related to traumatic stress and posttraumatic stress disorder. Psychoneuroendocrinology. 2015;51:506-12.

29. van Zuiden M, Geuze E, Willemen HL, Vermetten E, Maas M, Heijnen CJ, Kavelaars A. Pre-existing high glucocorticoid receptor number predicting development of posttraumatic stress symptoms after military deployment. Am J Psychiatry. 2011;168:89-96.

30. Ashley-Koch AE, Garrett ME, Gibson J, Liu Y, Dennis MF, Kimbrel NA. Veterans Affairs Mid-Atlantic Mental IIIness Research E, Clinical Center W, Beckham JC, Hauser MA: Genome-wide association study of posttraumatic stress disorder in a cohort of Iraq-Afghanistan era veterans. J Affect Disord. 2015;184:225-34.

31. McAllister TW, Zafonte R, Jain S, Flashman LA, George MS, Grant GA He F, Lohr JB, Andaluz N, Summerall L, et al. Randomized placebocontrolled trial of methylphenidate or galantamine for persistent emotional and cognitive symptoms associated with PTSD and/or traumatic brain injury. Neuropsychopharmacology. 2016;41:1191-8.

32. Rasmusson AM, Marx CE, Jain S, Farfel GM, Tsai J, Sun X, Geracioti TD, Hamner MB, Lohr J, Rosse R, et al. A randomized controlled trial of ganaxolone in posttraumatic stress disorder. Psychopharmacology (Berl). 2017;234:2245-57

33. Lepage C, de Pierrefeu A, Koerte IK, Coleman MJ, Pasternak O, Grant G, Marx CE, Morey RA, Flashman LA, George MS, et al. White matter abnormalities in mild traumatic brain injury with and without posttraumatic stress disorder: a subject-specific diffusion tensor imaging study. Brain Imaging Behav. 2018;12:870-81.

34. Fonzo GA, Goodkind MS, Oathes DJ, Zaiko YV, Harvey M, Peng KK, Weiss ME, Thompson AL, Zack SE, Mills-Finnerty CE, et al. Selective effects of psychotherapy on frontopolar cortical function in PTSD. Am J Psychiatry. 2017;174:1175-84.

35. Morrison FG, Miller MW, Wolf EJ, Logue MW, Maniates H, Kwasnik D, Cherry JD, Svirsky S, Restaino A, Hildebrandt A, et al. Reduced interleukin 1A gene expression in the dorsolateral prefrontal cortex of individuals with PTSD and depression. Neuroscience Letters. Mol Psychiatry. 2016;21(3):357-63.

36. Sadeh N, Spielberg JM, Logue MW, Wolf EJ, Smith AK, Lusk J, Hayes JP, Sperbeck E, Milberg WP, McGlinchey RE, et al. SKA2 methylation is associated with decreased prefrontal cortical thickness and greater PTSD severity among trauma-exposed veterans. Mol Psychiatry. 2016;21: 357-63.

37. Ratanatharathorn A, Boks MP, Maihofer AX, Aiello AE, Amstadter AB, AshleyKoch AE, Baker DG, Beckham JC, Bromet E, Dennis M, et al. Epigenome-wide association of PTSD from heterogeneous cohorts with a common multi-site analysis pipeline. Am J Med Genet B Neuropsychiatr Genet. 2017;174:619-30.

38. Ritchie ME, Phipson B, Wu D, Hu Y, Law CW, Shi W. Smyth GK: limma powers differential expression analyses for RNA-sequencing and microarray studies. Nucleic Acids Res. 2015;43:e47.

39. Benjamini $Y$, Hochberg $Y$. Controlling the false discovery rate: a practical and powerful approach to multiple testing. J R Statist Soc B. 1995;57:289-300.

40. Phipson B, Maksimovic J. Oshlack A: missMethyl: an R package for analyzing data from Illumina's HumanMethylation450 platform. Bioinformatics. 2016; 32:286-8.

41. Young MD, Wakefield MJ, Smyth GK, Oshlack A. Gene ontology analysis for RNA-seq: accounting for selection bias. Genome Biol. 2010;11:R14.

42. Maddox SA, Kilaru V, Shin J, Jovanovic T, Almli LM, Dias BG, Norrholm SD, Fani N, Michopoulos V, Ding Z, et al. Estrogen-dependent association of HDAC4 with fear in female mice and women with PTSD. Mol Psychiatry. 2018;23:658-65.

43. Uddin M, Ratanatharathorn A, Armstrong D, Kuan PF, Aiello AE, Bromet EJ, Galea S, Koenen KC, Luft B, Ressler KJ, et al. Epigenetic meta-analysis across three civilian cohorts identifies NRG1 and HGS as blood-based biomarkers for post-traumatic stress disorder. Epigenomics. 2018;10(12):1585-601. 
44. Guintivano J, Aryee MJ, Kaminsky ZA. A cell epigenotype specific model for the correction of brain cellular heterogeneity bias and its application to age, brain region and major depression. Epigenetics. 2013;8:290-302.

45. Logue MW, Smith AK, Wolf EJ, Maniates H, Stone A, Schichman SA, McGlinchey RE, Milberg W, Miller MW. The correlation of methylation levels measured using Illumina 450K and EPIC BeadChips in blood samples. Epigenomics. 2017;9:1363-71.

46. Stimson RH, Anderson AJ, Ramage LE, Macfarlane DP, de Beaux AC, Mole DJ, Andrew R, Walker BR. Acute physiological effects of glucocorticoids on fuel metabolism in humans are permissive but not direct. Diabetes Obes Metab. 2017;19:883-91

47. Daskalakis NP, Cohen H, Cai G, Buxbaum JD, Yehuda R. Expression profiling associates blood and brain glucocorticoid receptor signaling with traumarelated individual differences in both sexes. Proc Natl Acad Sci U S A. 2014; 111:13529-34.

48. Bam M, Yang X, Zumbrun EE, Zhong Y, Zhou J, Ginsberg JP, Leyden Q, Zhang J, Nagarkatti PS, Nagarkatti M. Dysregulated immune system networks in war veterans with PTSD is an outcome of altered miRNA expression and DNA methylation. Sci Rep. 2016:6:31209.

49. Heckmann BL, Zhang X, Xie X, Liu J. The G0/G1 switch gene 2 (G0S2): regulating metabolism and beyond. Biochim Biophys Acta. 1831;2013:276-81.

50. Zhang X, Heckmann BL, Campbell LE, Liu J. GOS2: a small giant controller of lipolysis and adipose-liver fatty acid flux. Biochim Biophys Acta Mol Cell Biol Lipids. 1862;2017:1146-54.

51. Li CW, Wang WH, Chen BS. Investigating the specific core geneticand-epigenetic networks of cellular mechanisms involved in human aging in peripheral blood mononuclear cells. Oncotarget. 2016;7: 8556-79.

52. Wolf E, Sadeh N, Leritz EC, Logue MW, Stoop TB, McGlinchey R, Milberg W, Miller MW. Posttraumatic stress disorder as a catalyst for the association between metabolic syndrome and reduced cortical thickness. Biol Psychiatry. 2016;80:363-71.

53. Wolf E, Miller DR, Logue MW, Sumner J, Stoop TB, Leritz EC, Hayes JP, Stone A, Schichman SA, McGlinchey RE, et al. Contributions of polygenic risk for obesity to PTSD-related metabolic syndrome and cortical thickness. Brain Behav Immun. 2017; 65:328-36

54. Hannon E, Lunnon K, Schalkwyk L, Mill J. Interindividual methylomic variation across blood, cortex, and cerebellum: implications for epigenetic studies of neurological and neuropsychiatric phenotypes. Epigenetics. 2015;10:1024-32.

55. Braun PR, Han S, Hing B, Nagahama Y, Gaul LN, Heinzman JT, Grossbach AJ, Close L, Dlouhy BJ, Howard MA 3rd, et al. Genome-wide DNA methylation comparison between live human brain and peripheral tissues within individuals. Transl Psychiatry. 2019;9:47.

56. Komaki S, Shiwa Y, Furukawa R, Hachiya T, Ohmomo H, Otomo R, Satoh M, Hitom J, Sobue K, Sasaki M, Shimizu A. iMETHYL: an integrative database of human DNA methylation, gene expression, and genomic variation. Hum Genome Var. 2018;5: 18008

57. Hachiya T, Furukawa R, Shiwa Y, Ohmomo H, Ono K, Katsuoka F, Nagasaki M, Yasuda J, Fuse N, Kinoshita K, et al. Genome-wide identification of inter-individually variable DNA methylation sites improves the efficacy of epigenetic association studies. NPJ Genom Med. 2017;2:11.

58. Walker DG, Link J, Lue LF, Dalsing-Hernandez JE, Boyes BE. Gene expression changes by amyloid beta peptide-stimulated human postmortem brain microglia identify activation of multiple inflammatory processes. J Leukoc Biol. 2006;79:596-610.

59. Gao X, Jia M, Zhang $Y$, Breitling LP, Brenner $H$. DNA methylation changes of whole blood cells in response to active smoking exposure in adults: a systematic review of DNA methylation studies. Clin Epigenetics. 2015;7:113

60. Gao X, Zhang Y, Breitling LP, Brenner H. Relationship of tobacco smoking and smoking-related DNA methylation with epigenetic age acceleration. Oncotarget. 2016;7:46878-89.

61. Ligthart S, Marzi C, Aslibekyan S, Mendelson MM, Conneely KN, Tanaka T, Colicino E, Waite LL, Joehanes R, Guan W, et al. DNA methylation signatures of chronic low-grade inflammation are associated with complex diseases. Genome Biol. 2016;17:255.

62. Jiang $\mathrm{S}, \mathrm{Li} Y$, Z Zhang $X, B u \mathrm{G}, \mathrm{Xu} \mathrm{H}$, Zhang YW. Trafficking regulation of proteins in Alzheimer's disease. Mol Neurodegener. 2014;9:6.

63. Davies G, Marioni RE, Liewald DC, Hill WD, Hagenaars SP, Harris SE, Ritchie SJ, Luciano M, Fawns-Ritchie C, Lyall D, et al. Genome-wide association study of cognitive functions and educational attainment in UK Biobank ( $\mathrm{N}=$ 112 151). Mol Psychiatry. 2016;21:758-67.
64. Kristiansen LV, Bakir B, Haroutunian V, Meador-Woodruff JH. Expression of the NR2B-NMDA receptor trafficking complex in prefrontal cortex from a group of elderly patients with schizophrenia. Schizophr Res. 2010;119:198209.

65. Babatz TD, Kumar RA, Sudi J, Dobyns WB, Christian SL. Copy number and sequence variants implicate APBA2 as an autism candidate gene. Autism Res. 2009;2:359-64.

66. Kirov G, Gumus D, Chen W, Norton N, Georgieva L, Sari M, O'Donovan MC, Erdogan F, Owen MJ, Ropers HH, Ullmann R. Comparative genome hybridization suggests a role for NRXN1 and APBA2 in schizophrenia. Hum Mol Genet. 2008:17:458-65.

67. Teschler S, Bartkuhn M, Kunzel N, Schmidt C, Kiehl S, Dammann G, Dammann R. Aberrant methylation of gene associated CpG sites occurs in borderline personality disorder. PLoS One. 2013;8:e84180.

68. Miyata S, Kitagawa H. Chondroitin sulfate and neuronal disorders. Front Biosci (Landmark Ed). 2016;21:1330-40.

69. Banerjee SB, Gutzeit VA, Baman J, Aoued HS, Doshi NK, Liu RC, Ressler KJ. Perineuronal nets in the adult sensory cortex are necessary for fear learning. Neuron. 2017;95:169-79 e163.

70. Stephenson EL, Yong W. Pro-inflammatory roles of chondroitin sulfate proteoglycans in disorders of the central nervous system. Matrix Biol. 2018; 71-72:432-42.

\section{Publisher's Note}

Springer Nature remains neutral with regard to jurisdictional claims in published maps and institutional affiliations.

\section{Ready to submit your research? Choose BMC and benefit from:}

- fast, convenient online submission

- thorough peer review by experienced researchers in your field

- rapid publication on acceptance

- support for research data, including large and complex data types

- gold Open Access which fosters wider collaboration and increased citations

- maximum visibility for your research: over $100 \mathrm{M}$ website views per year

At $\mathrm{BMC}$, research is always in progress.

Learn more biomedcentral.com/submissions 